\title{
Theoretical and Experimental Study of a Micro Jet Engine Start-Up Behaviour
}

\author{
Morteza MONTAZERI-GH, Seyed Alireza Miran FASHANDI, Soheil JAFARI
}

\begin{abstract}
Proper functioning of the start-up process in a micro jet engine is of great importance. This is due to the fact that the combustion chamber of such engine is so small and therefore, there is little time for fuel and air mixture to be present in the chamber. Hence, failed starts or repetitive attempts by the electric starter are very likely due to non-formation of the initial combustion. Also, the performance of the turbine start-up, impressively affects the limited life time of the micro jet engine. In this paper, an experimental study on the injection of compressed air during the start-up of a micro jet engine to improve its performance has been conducted. For this purpose, test components' layout and a monitoring system are designed. The allowable pressure of the air injection has been calculated using both the engine dynamic model and experimental tests. The simulation results have also been compared and validated with the experimental test results. Finally, several tests were conducted to study the injection process of the compressed air form which, several results have been deduced including the reduction of maximum exhaust gas temperature (EGT) during the start-up, reduction of the start-up time interval and service lifetime enhancement. The method proposed in this paper is applicable on any micro jet engine with the similar structural form and starting process.
\end{abstract}

Keywords: dynamic modelling; experimental test; micro jet engine; start-up

\section{INTRODUCTION}

Limited lifetime of micro-jet engines is subjected to many factors such as the number of working hours, number of successful and unsuccessful starts, operating temperatures and etc. Some of these factors are related to the engine construction processes while others depend on the engine performance and how it is being controlled [1]. EGT during the start-up is a key parameter which represents the thermal stress on the engine and the combustion chamber overall operability condition.

At the time of the start-up, there is not sufficient airflow in the combustion chamber to be mixed with the fuel in order to start the combustion process due to compressor inactivity. To overcome this problem, a starter is used to deliver the required speed to the compressor so that the sufficient airflow for the combustion process is provided. The required energy for the start-up process depends on the type of the engine and its aircraft. Micro jet start-up phase is either electrical which is more frequent, or pneumatic. There are several ways to set up a pneumatic start-up [2].

One way is to use a blower system. Another way is to use a compressed air tank. In this case, the reservoir of compressed air is connected to the engine port via pipes through which the compressed air is injected to the engine. In an electric starter, an electric motor is connected to the compressor wheel in front of the engine so that the engine speed reaches a minimum limit required for the Ignition process. This speed will be called "ignition speed" throughout this paper.

As mentioned before, an electric starter motor is used for the start-up process of most micro jet engines. The primary combustion is with gas fuel in order to preheat the combustion chamber. After a few seconds, the liquid fuel is injected. The use of liquid fuel alone during the start-up incurs some problems. First, thermal unbalance occurs between the absorbed heat by the external vaporizer walls and the required heat for the vaporization process. Second, due to the fact that thermal inertia of the combustion system is increased by the addition of vaporizers, the transient response of the combustion system is affected through either overheating of the walls or partial fuel vaporization [3]. Another drawback is associated with the application of vaporizers during ignition. Vaporization process could not be rendered while the walls of the vaporizer and the combustor's liner are still cold, because the liquid fuel keeps its liquid state even through the exit [4]. So in micro jet engines, including the engine in this study, which is equipped with vaporizers, the use of gas fuel during the ignition process is indispensable. Small geometrical dimensions entail some problems in the combustion chamber as well. In order for the fuel and air mixture to be homogenous, which is essential for the combustion process, the fuel has to be atomized and then be mixed with the air. If the combustor dimensions are small, the presence of this flammable mixture in the chamber is too short. Therefore vaporization processes along with fuel atomizing process have to be fast and simple [5]. Also small engines cannot operate at high pressure ratios (Working pressure ratios: $\operatorname{Pr}_{c}=2 \ldots$ 4). As a consequence, air temperature at the combustor inlet is limited up to $T_{t 3} \approx 400 \ldots 450 \mathrm{~K}$, therefore additional heat is needed in the combustion chamber for fuel vaporization. Eq. (1) demonstrates the relation between the temperature rise and the pressure ratio. With regard to economic requirements, complex and expensive technologies have to be avoided in order to keep the sales price as competitive as possible [6].

$\frac{T_{t 3}}{T_{t 2}}=\operatorname{Pr}_{c}{ }^{\frac{1}{\eta_{c}} \frac{k-1}{k}}$

where $P r_{c}$ and $\eta_{c}$ respectively represent the pressure ratio and efficiency of compressor. $k$ is the specific heat ratio, $T_{t 2}$ is the temperature at the compressor inlet, $T_{t 3}$ and is the temperature at the compressor outlet.

So far, few studies have been performed on modelling and optimization of the start-up phase of small gas turbine engines. The use of software models for estimating the dynamic behaviour of micro jet engines has attracted the attention of many researchers [7-9]. In 
general, the usage of a starter unit is essential for any system containing a combustion engine [10].

Start-up phase is one of the most common unstable states in gas turbine engines. Since the gas turbine performance during the start-up has a considerable impact on the engine's life time, therefore it is necessary for any designer to have a simulation program to assess the gas turbine engine's performance in this phase. In other words, in order to analyse the engine performance during the start-up phase, a reliable engine model for this phase is needed. In 2012 Madarasz [11], investigated a digital control for the start-up of a small turbojet engine. In 2012, another study was performed by Baoan and Fan [12] regarding modelling and simulation for the ground startup of a small turbojet engine [12]. They divided the startup process into three phases. In the first phase, the small turbojet engine is run by an electric motor without any ignition. Second, ignition occurs and the electric motor continues to work. In the third phase, only the turbine provides the required acceleration for the system. In 2013, the Xia et al. conducted an investigation on the characteristics and behaviour of micro turbine engines for windmill start-up process by means of three-dimensional numerical simulations and field tests [13]. In 2015, Montazeri [14] investigated the cold start-up modelling of a micro jet engine by bond graph approach. In 2015, Dub [15] designed and built an electronic control unit for the start-phase of a small jet engine.

According to the cited literature review, available published documents about the start-up of micro jet engines are very limited.

As mentioned earlier, the possibility of an unsuccessful start-up or repeating the start-up process by the electric starter because of non-formation of the primary combustion is very likely. The occurrence of such events can reduce the limited life time of the microjet engine. Due to the complexity of the start-up of microjet engines, experimental tests along with engine modelling are not only essential but inevitable. These tests are also dangerous and costly.

In this paper, in order to improve the performance of the micro-jet engine's start-up process, compressed air is injected into the engine during the start-up which results in EGT and time duration reduction in the start-up. In order to determine the maximum allowable pressure for air injection, experimental tests have been carried out along with dynamic modelling via bond graph approach.

The outline of this paper is as follows: First, the studied engine is introduced in section two. Then the test bed and monitoring system design are described in the third section. The electric start-up is discussed later in section four. In the fifth section, compressed air injection during the start-up of experimental tests has been performed. Later, bond-graph modelling of the micro-jet engine's start-up is conducted and the simulation results are compared with those from the experiments. Then, various tests with electric starter and compressed air injection have been carried out and finally the results are evaluated.

\section{THE MICRO JET ENGINE}

The engine under study is a mechatronic system with a smart electronic control unit. This microprocessor-based unit has a duty to observe the entire engine's controlling modes simultaneously and respecting the physical and structural reliabilities at the same time.

A schematic of the engine is shown in Fig. 1. It comprises a single-stage radial compressor, a single-stage axial flow turbine, an annular combustion chamber and a nozzle. Also, the electric starter and the compressed air tank with a valve, to inject compressed air, are demonstrated in this figure. The electronic control unit is fully automated therefore it does not need to be adjusted by an operator. The whole processes of the start-up, cooling and shutdown are performed by the ECU automatically. Some of the technical specifications and engine dimensions can be seen in Tab. 1.

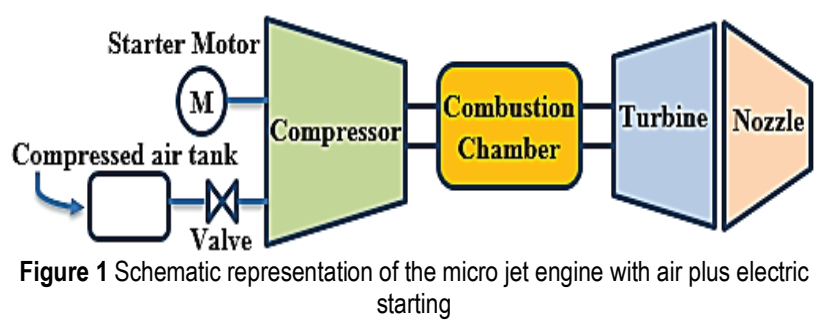

Table 1 Micro jet engine specifications

\begin{tabular}{|l|c|}
\hline \multicolumn{1}{|c|}{ Technical data } & Value \\
\hline Length (electric-start) & $385 \mathrm{~mm}$ \\
\hline System weight (electric-start) & 4575 gram \\
\hline Maximum RPM & 97500 \\
\hline Maximum EGT & $829^{\circ} \mathrm{C}$ \\
\hline Pressure ratio @ max. rpm & 3.8 \\
\hline
\end{tabular}

\section{TEST BED AND MONITORING SYSTEM DESIGN}

Since the engine's commercial software does not provide the performance information from the start-up until the ignition occurs, a monitoring system in Lab view software [16] is designed to accurately sample the data from the start-up. The serial communication with the electronic control unit enables the system to store and demonstrate the engine performance parameters at the same time. In general, the ECU of the majority of jet engines is provided with an output serial port for communication and data exchange via RS-232 standard. The designed monitoring system can be seen in Fig. 2. The engine performance parameters such as EGT, speed, throttle changes and fuel pump voltage variations are displayed, their values are calculated and stored. In the case of a system error, the error type (according to the engine) is specified in the designed page. The accuracies of the EGT and speed sensors are demonstrated in Tab. 2. In the process of injecting compressed air, the corresponding valve command is generated by an auxiliary start-up unit in which the engine speed is being measured and compared with the desired speed after data processing. While the engine speed is far less than the set value, the valve remains open. On the other hand, the valve is closed as soon as the speed reaches that limit. In 
this process, the compressed air is responsible for the engine speed variations

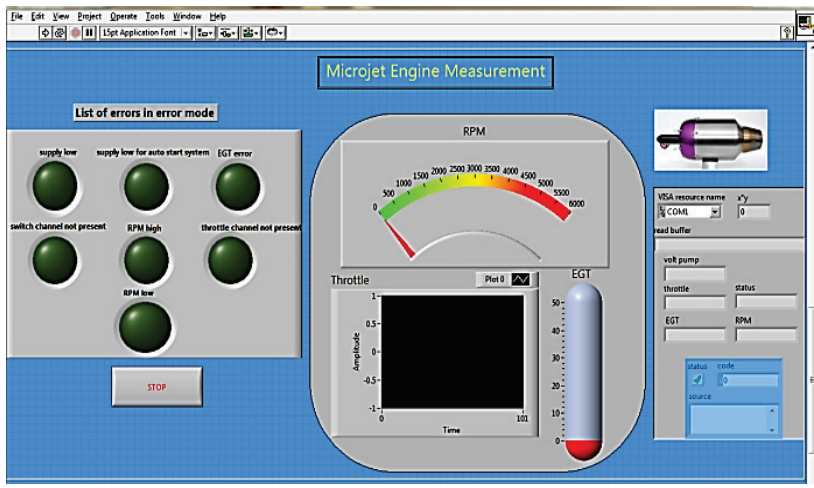

Figure 2 Monitoring system

Table 2 Accuracy of sensors

\begin{tabular}{|c|c|}
\hline Measurement & Accuracy \\
\hline RPM value & $\pm 500 \mathrm{rev} / \mathrm{min}$ \\
\hline EGT value & $\pm 5^{\circ} \mathrm{C}$ \\
\hline
\end{tabular}

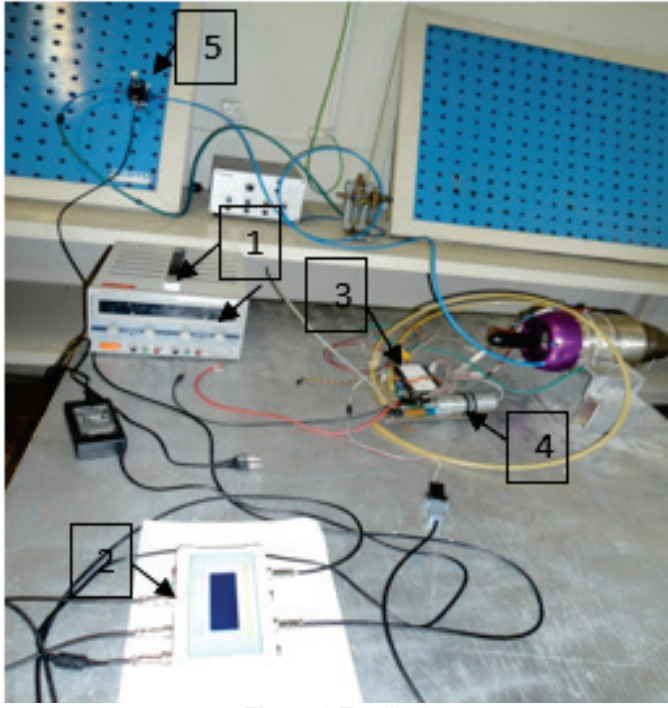

Figure 3 Test bed

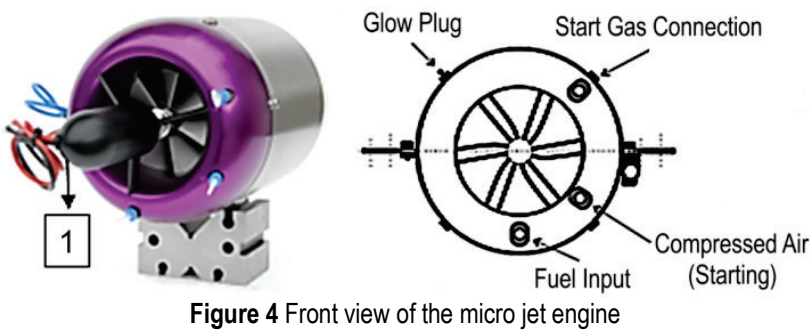

It is noteworthy to mention that the studied engine had only been equipped with an electric starter. Compressed air injection equipment, including the auxiliary start-up unit and the electro-pneumatic valve has been provided by the simulation and control system laboratory. Components used for the tests on the micro-jet engine and data acquisition are: the computer on which the monitoring software has been installed, electropneumatic valve (Fig. 3 - No. 5), auxiliary start-up unit (Fig. 3 - No. 2), ECU (Fig. 3 - No. 3), fuel pump (Fig. 3 - No. 4), gas fuel (propane), liquid fuel, radio control, power supply (Fig. 3 - No. 1), the electric starter (Fig. 4 No. 1). Data acquisition and storage has been performed by the serial port via standard RS-232. Compressed air is injected through the specified port in Fig. 4.

\section{ELECTRICAL START-UP PROCESS}

After preparing and connecting all components, monitoring system program runs on the $\mathrm{PC}$ and the engine is started by the radio control. After the start of the electric starter, the compressor speed is brought to the ignition speed and then the starter goes off, however the propane (gas fuel) is still being injected into the combustion chamber. After propane combustion, the electric motor restarts and drives the engine up to a certain speed. When the EGT and engine speed reach a certain level, fuel is forwarded to the combustion chamber by the fuel pump. After the completion of fuel combustion, the engine speed is throttled up to the calibration level by the ECU automatically and maintains that speed for a short time, then it is reduced to idle. Therefore, idle speed has been calibrated. ECU performs all these steps automatically. After passing through this phase, the operator can reach his desired thrust rate and speed by the radio-control. In Fig. 5 a schematic trend of micro-jet engine start-up sequence has been presented.

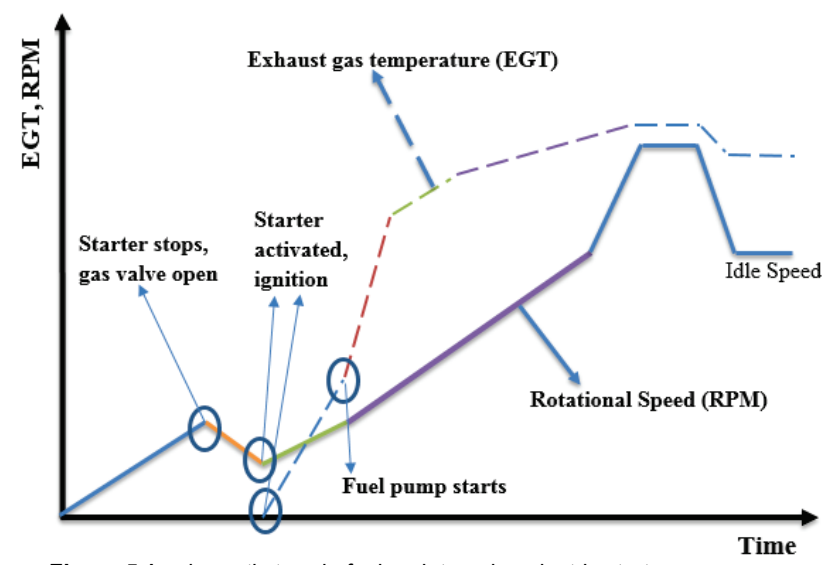

Figure $5 \mathrm{~A}$ schematic trend of micro-jet engine electric start-up sequence

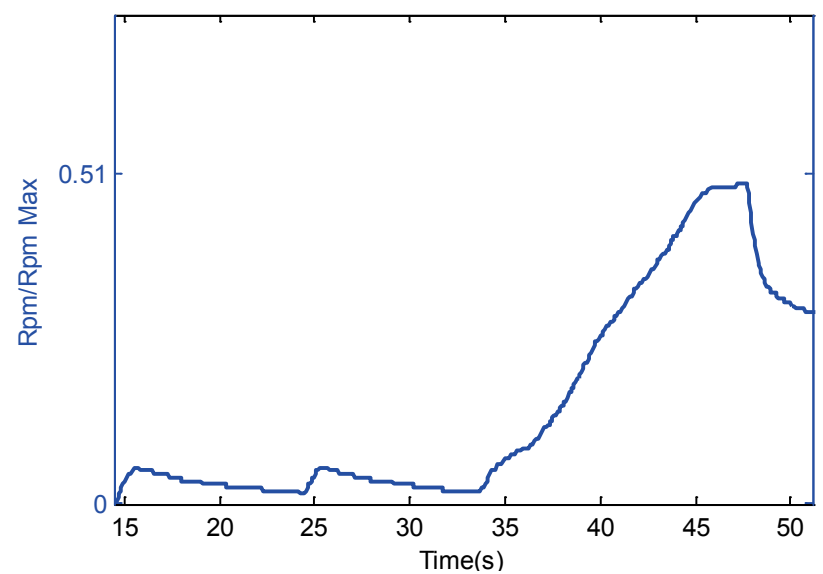

Figure 6 A section of electric start-up sequence

In some cases, due to either environmental conditions or the uncoordinated performance of start-up components, the start-up process cannot be formed. In Fig. 6, the electric starter in the cold start-up has been activated twice due to the lack of primary combustion of the propane. This increases the engine start-up time. The 
results shown in the graphs were normalized to the Maximum operating point (Tab. 2).

Fig. 7 shows a section of a failed engine start-up during which the engine has not reached the specified speed limit. The start-up process cannot be formed because of the lack of balance between shaft speed and EGT.

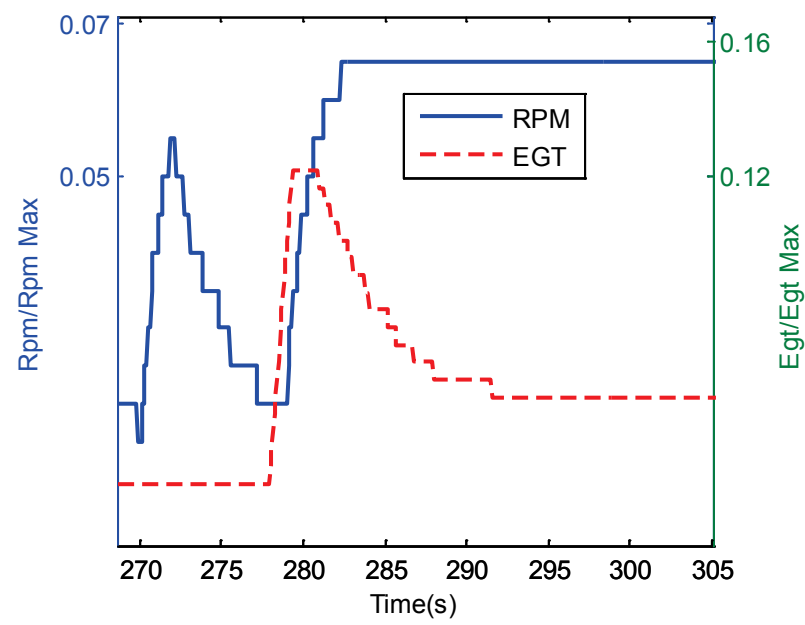

Figure $7 \mathrm{~A}$ section of a failed engine electric start-up sequence

\section{COMPRESSED AIR INJECTION DURING THE START- UP IN EXPERIMENTAL TESTS}

In this section, the following tests are used to determine the allowable air pressure. For these tests, an electro-pneumatic valve is used. This solenoid-induction valve controls the pressure and air flow fed to the engine. Compressed air of the tank enters the valve and is directed to a port in front of the engine, causing the compressor vanes to rotate. Schematic of the compressed air injection system is shown in Fig. 8. Auxiliary start-up unit sends a command to the valve. Air injection with different pressures affects the propane combustion. For this purpose, experimental tests have been performed to determine the effects of air pressure on the performance of propane combustion. In Fig. 8, EGT variations are shown from the beginning of the propane combustion until the fuel pump activation for 4 different tests.

Tests $\mathrm{A}$ and $\mathrm{B}$ in Fig. 8 indicate the EGT changes when only starter is activated and propane combustion has occurred. But tests C and D represent the EGT changes when the compressed air is injected and then the starter is activated and propane combustion has occurred. In detail, tests $\mathrm{A}, \mathrm{B}$ and $\mathrm{C}$ are described in section seven. According to the test results, the injection of compressed air makes the EGT more inclined than just a starter. The higher EGT reaches, the quicker the fuel pump can be activated during the start sequence. As mentioned earlier, when EGT and engine speed reach a certain limit, the fuel pump is activated. Effect of compressed air injection on propane combustion will optimally preheat the combustor, which according to the micro jet engine combustor structure described in the introduction, is preferable. During the starting process, propane ignition is the basis of fuel evaporation and atomization, straightly affecting the success of fuel ignition. Due to the results, chemical reaction kinetics of propane combustion is dependent on the air pressurized. In other words, the more the injected air pressure, the better the propane combustion performance.

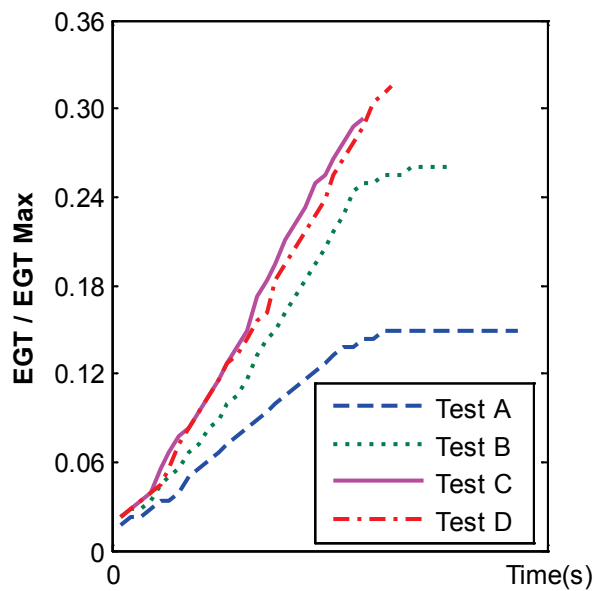

Figure 8 Variations in EGT in propane combustion of start-up process

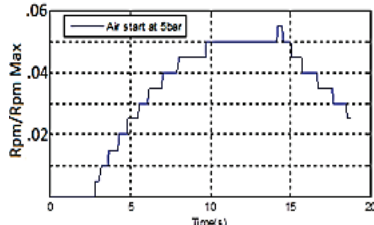

(a)

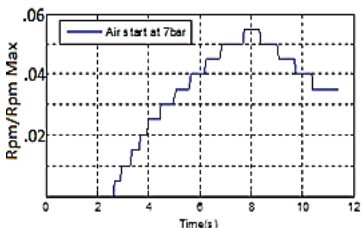

(c)

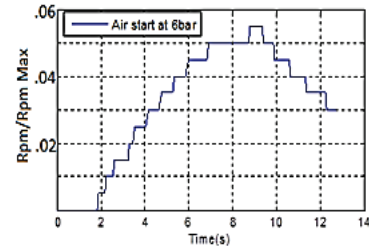

(b)

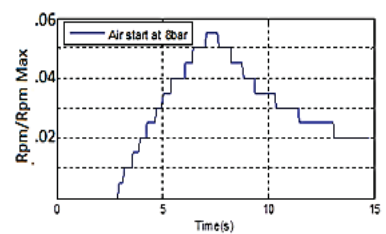

(d)
Figure 9 Relation between the air injection pressure and the engine speed: (a) air pressure: 5 bar, (b) air pressure: 6 bar, (c) air pressure: 7 bar, (d) air pressure: 8 bar.

On the other hand, Fig. 9 demonstrates the relation between the air injection pressure and the engine speed. The results of these tests will be used to identify the parameters of bond-graph model.

\section{BOND-GRAPH MODEL OF THE MICRO-JET ENGINE WITH ELECTRIC STARTER AND COMPRESSED AIR INJECTION}

Electric starter and compressed air injection models have been developed in [14] in which a simplified model for dynamic behaviour of a micro-jet engine has been considered. For more information on the electric starter and compressed air injection and bond graph model, refer to [14]. Engine Bond-graph model is shown in Fig. 10.

Fig. $11 \mathrm{~b}$ shows the simulation results when only the electric starter is activated. On the other hand, the effect of compressed air injection in the simulation is demonstrated in Fig. 11a. As could be seen in these figures, the accuracy of the simulation results is acceptable.

Whereas the starter is turned off by the ECU in the cold start-up after reaching the ignition speed, first compressed air with different pressures is injected into the 
engine in the simulation until the engine speed reaches a certain limit, then the starter is activated. At this point, engine speed can be increased even more than the ignition speed which would result in a sudden impulse and damage to the starter bearings and its clutch. In these simulations, the maximum allowable speed caused by air pressure is $2500 \mathrm{rpm}$. The pressure of injected air allows the maximum engine speed to reach $2500 \mathrm{rpm}$, then the starter activates. So in this section, allowable pressure of the incoming air is determined by the simulation to avoid damaging the starter system itself. Then, with the engine dynamic model and experimental tests, the allowable pressure for air injection is calculated and applied into the tests.

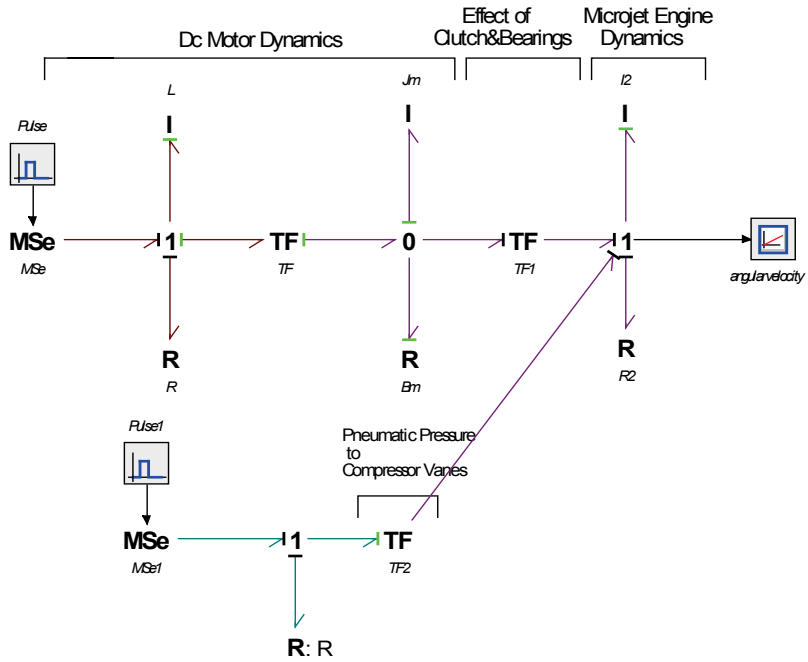

Figure 10 Engine bond graph model

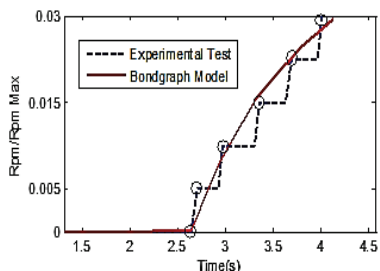

(a)

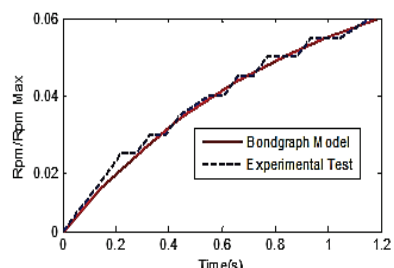

(b)
Figure $11 \mathrm{~A}$ comparison of engine simulation and test results with: (a) compressed air injection (b) electric starter

\section{EXPERIMENTAL AND ANALYTICAL STUDY OF COMPRESSED AIR INJECTION DURING THE START- UP}

Several other tests involving the electric starter and compressed air injection during the start-up were conducted, the results of which are presented in the following figures. All of them have been normalized with respect to the Maximum operating point (Tab. 1). Ambient conditions were the same for all of the tests. Also the data were corrected due to the ambient pressure and temperature.

Different engine parameters' deviations during the start-up are in accordance with how the start-up process is enforced. In other words, the number of electric starter activation and times of ignition and primary combustion affect the start-up performance. Fig. 12 represents engine speed and EGT for test A from the beginning of start-up. According to Fig. 12, electric starter has started in around the $9^{\text {th }}$ second (Fig. $12-$ No. 1) and at the same time gas injection valve has been opened. After engine speed is high enough for ignition, electric starter goes off and the Glow plug is activated to initiate the combustion by Propane. This can be observed with the increase of EGT around the 19th second. Propane combustion takes 3.58 seconds in test A, specified by a box in the figure (Fig. 12 - No. 2).

After initial ignition, electrical starter is re-activated at $2000 \mathrm{rpm}$ (Fig. 12 - No. 3) and engine speed is increased. At this time, when engine speed and EGT have reached a certain value, fuel pump is activated by the ECU in the $21.46^{\text {th }}$ second (Fig. 12 - No. 4), therefore liquid fuel is injected to the engine and accelerating starts. According to figure 13, fuel pump activation time during the hot start-up in this test is 14.15 seconds. The maximum EGT in test A during the start-up is $828.6^{\circ} \mathrm{C}$. After combustion, engine speed is throttled up to the calibration speed (Fig. 12 - No. 5), by the ECU and maintains this speed at 35 th second. Then it is reduced to idle speed (Fig. 12 - No. 6) automatically. At this time, idle speed has been calibrated.

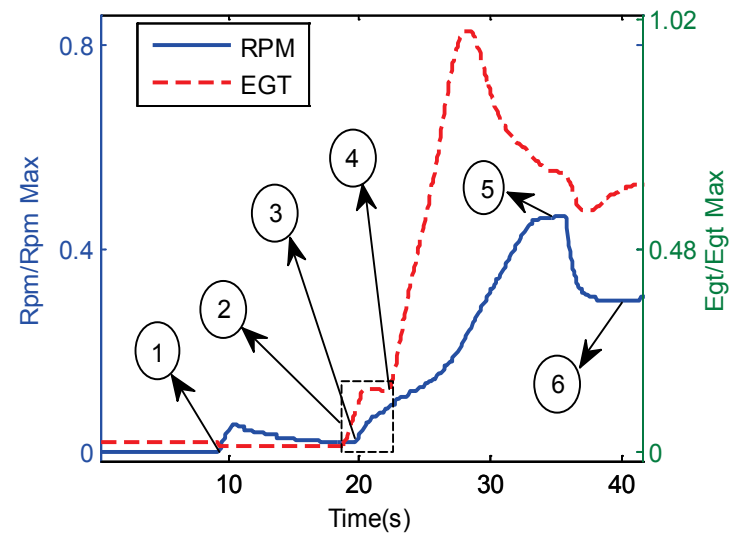

Figure 12 Variations in RPM and EGT vs. time, in electric starting Test A

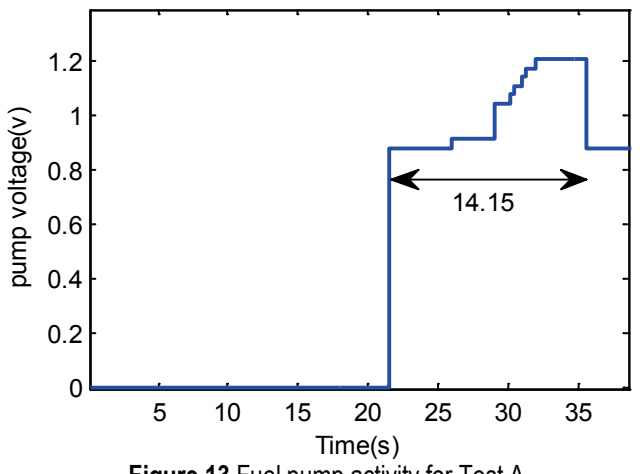

Figure 13 Fuel pump activity for Test $\mathrm{A}$

Fig. 14 shows the results of changes in the speed and EGT for test B from the start-up and after. In Fig. 14, the electric starter has been activated at the $11^{\text {th }}$ second (Fig. 14 - No. 1) and delivered the engine's speed up to the ignition speed, but due to non-formation of propane combustion, this process is repeated three times until combustion finally happened. This increases the engine start-up time. In the second and third attempts at about the $19.7^{\text {th }}$ and $27.5^{\text {th }}$ seconds, the electric starter is activated after 1500 rpm (Fig. 14 - No. 2). Each gas turbine engine 
has an allowed number for start-up repeat cycle with a specified time lag.

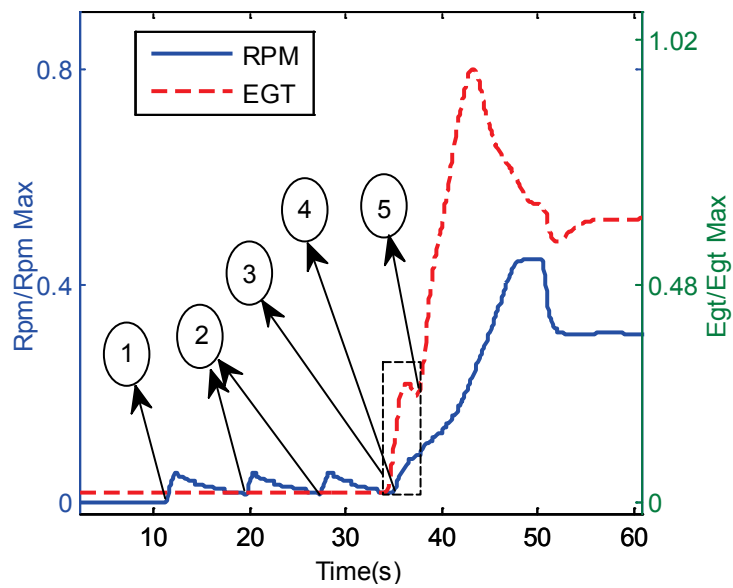

Figure 14 Variations in RPM and EGT vs. time, in electric starting Test B

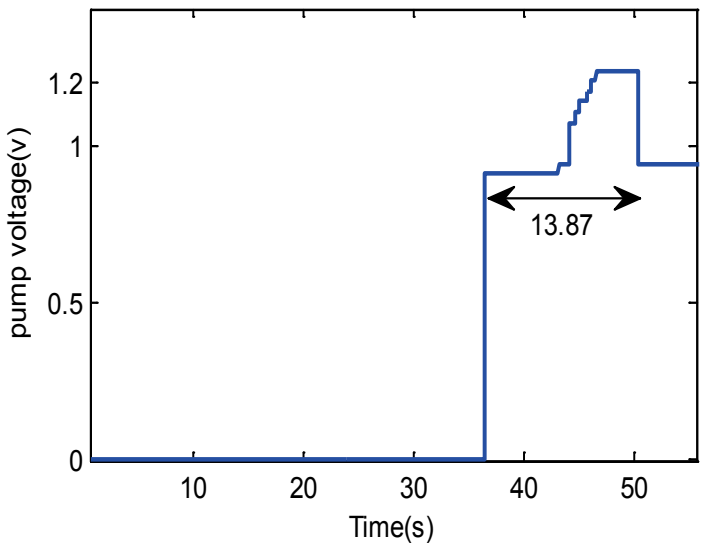

Figure 15 Fuel pump activity for Test B

Propane combustion lasts for 3.47 seconds in test B which is shown by a box (Fig. $14-$ No. 3 ) in the figure. After initial ignition, electrical starter is re-activated at $2000 \mathrm{rpm}$ (Fig. 14 - No. 4) and the engine speed is increased. At this time, when EGT and engine speed have reached a certain value, fuel pump is activated (Fig. 14 No. 5) by the ECU at the $36^{\text {th }}$ second, liquid fuel injection begins and the engine starts accelerating. As could be seen in Fig. 15, fuel pump runs for 13.87 seconds in the hot start-up. Also the maximum EGT is about $796.4{ }^{\circ} \mathrm{C}$ in test B.

The results of the compressed air injection implementation at the start-up of test $\mathrm{C}$ is shown in Fig. 16. In order to implement the proposed idea, at first, compressed air is injected towards the compressor blades by an electro-pneumatic valve through the tube port and engine speed is increased. As is seen in the figure, compressed air has been injected for 43 seconds (Fig. 16 - M) and engine speed reaches $2500 \mathrm{rpm}$. Then the electric starter is enabled (Fig. $16-$ No. 1). The valve is controlled automatically by the start-up auxiliary unit. Propane combustion takes 2.41 seconds in test $\mathrm{C}$ which is indicated by a box in the figure (Fig. 16 - No. 2). After initial ignition, electrical starter is re-activated at 3500 rpm (Fig. 16 - No. 3) and the engine speed adds up. When speed and EGT have reached a certain level, fuel pump is activated (Fig. $16-$ No. 4 ) by the ECU in the $50^{\text {th }}$ second and liquid fuel injection initiates and the engine accelerates. Also the maximum EGT is about $791.8^{\circ} \mathrm{C}$ in test $\mathrm{C}$. As could be seen in Fig. 17, fuel pump runs for 13.48 seconds in the hot start-up.

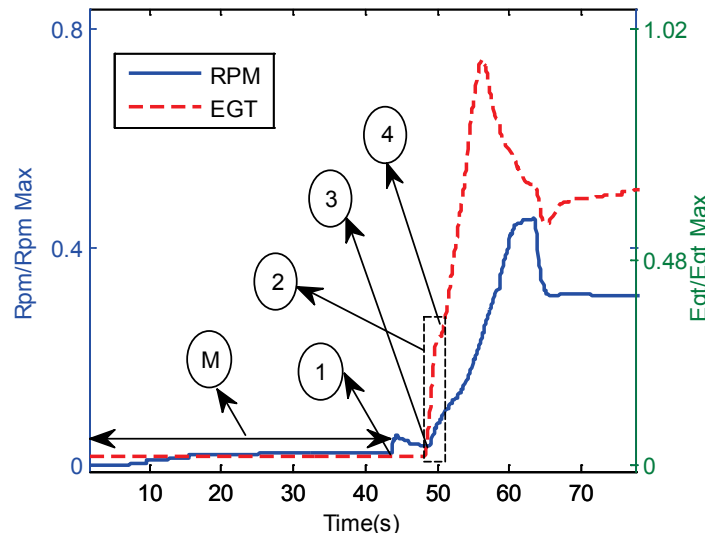

Figure 16 Variations in RPM and EGT vs. time in the air plus electric starting Test C

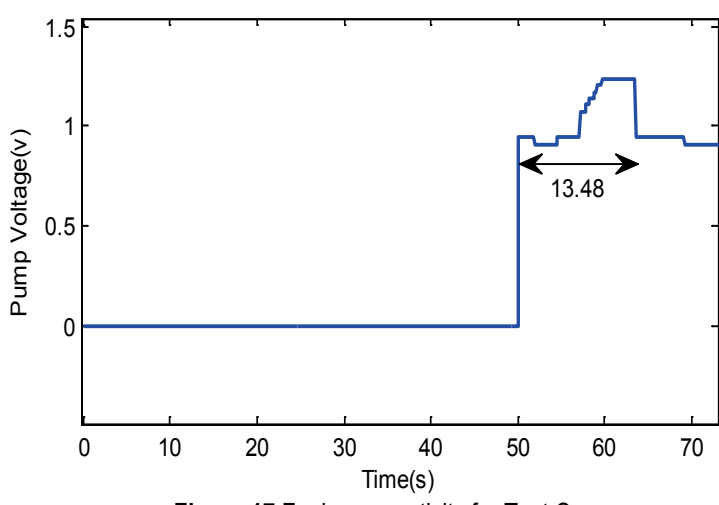

Figure 17 Fuel pump activity for Test $\mathrm{C}$

As is evident in Fig. 16, by compressed air injecting, the start-up sequence changes and the initial combustion of the propane improves as well. In other words, the propane combustion time has been reduced in comparison to the test in which only the electric starter had operated. Also, after the initial ignition, the electrical starter has begun its activities at higher engine speed than the case with just an electric starter. These two factors have let the speed and EGT approach to their specified value so much faster and thus, the liquid fuel pump is activated more quickly. Compressed Injection air also prevents repetition of the start-up process due to unsuccessful initial combustion. A thorough study of the results of test C, with regard to the hot start-up transient condition elapsed time, suggests that the fuel pump activation time (Fig. $17)$, has been reduced to 13.48 seconds, which shows a $4.7 \%$ and $2.8 \%$ improvement with respect to test $\mathrm{A}$ and test $\mathrm{B}$ respectively. As is seen in Fig. 16, air injection during start-up reduces the maximum EGT in this phase which shows a $4.4 \%$ and $0.6 \%$ reduction compared with test $\mathrm{A}$ and test $\mathrm{B}$. These results will increase the service life time of the engine and are important considering the limited life time of micro jet engines.

\section{CONCLUSION}

In a start-up process, the performance of most engine components is far from their design point, so 
understanding the details of the start-up phase, to ensure reliable and optimized engine performance is crucial. In this paper, a theoretical and experimental study of a micro-jet engine start-up phase was conducted. Also the effect of compressed air injection for start-up quality improvement was discussed. At first a monitoring system was designed in Lab view software in order to accurately sample the data from the start-up process. Then, with the engine dynamic model and experimental tests, the allowable pressure for air injection was calculated. Finally, several tests were conducted utilizing the electric starter and compressed air injection during the start-up, the results of which indicated that the air injection not only shortens the start-up and fuel pump activation, but it reduces the maximum EGT as well. These results are significant regarding the limited life time of micro-jet engines. The method proposed in this paper is applicable on any micro jet engine with the same starter studied in this research.

\section{NOMENCLATURE}

ECU - Electronic Control Unit

EGT - Exhaust Gas Temperature

RPM - Rotational Speed (revolutions per minute)

\section{REFERENCES}

[1] Prakash, R., Rao, S., \& Skarvan, C. A. (1990). Life Enhancement of a Gas Turbine Engine by Temperature Control. International Journal of Turbo and Jet Engines, 7(3), 187-206. https://doi.org/10.1515/TJJ.1990.7.3-4.187

[2] Walsh, P. P. \& Fletcher, P. (2004). Gas turbine performance, John Wiley \& Sons. https://doi.org/10.1002/9780470774533

[3] Levy, Y., Lipkin, S., Nadvany, V., \& Sherbaum, V. January. (2002). Fuel Atomization in Small Jet Engines. ASME Turbo Expo 2002: Power for Land, Sea, and Air. American Society of Mechanical Engineers, 759-763. https://doi.org/10.1115/GT2002-30586

[4] Levy, Y., Sherbaum, V., Nadvany, V., \& Nehkamkin, Y. (2006). Modified vaporizer for improved ignition in small jet engine. Journal of propulsion and power, 22(4), 828834. https://doi.org/10.2514/1.11008

[5] Fabian, F. (2016). Challenges in designing very small jet engines - fuel distribution and atomization. International Symposium on Transport Phenomena and Dynamics of Rotating Machinery / Hawaii, Honolulu, April 10-15, 2016.

[6] Kamps, T. (2005). Model Jet Engines, Traplet Publications.

[7] Leylek, Z., Anderson, W. S., Rowlinson, G., \& Smith, N. (2013). An Investigation into Performance Modeling of a Small Gas Turbine Engine. ASME Turbo Expo 2013. Turbine Technical Conference and Exposition (pp. V05AT23A007-V05AT23A007). American Society of Mechanical Engineers, San Antonio, Texas, USA. https://doi.org/10.1115/GT2013-94405

[8] Kong, C., Kho, S., \& Park, G. (2014). Development of Practical Integral Condition Monitoring System for a Small Turbojet Engine Using Matlab/Simulink and Labview. International Journal of Turbo \& JetEngines, 31(4), 173-186. https://doi.org/10.1515/tij-2013-0030

[9] Pakmehr, M., Fitzgerald, N., Feron, E. M., Shamma, J. S., \& Behbahani, A. (2014). Gain scheduled control of gas turbine engines: Stability and verification. Journal of engineering for Gas turbines and power, 136(3), 31-81.
[10] Fuvesi, V. \& Kovács, E. (2014). Modeling loaded starter motor with neural network. Computational Intelligence and Informatics (CINTI), IEEE $12^{\text {th }}$ International Symposium / Budapest.

[11] Madarasz, L., Karol, T., Gaspar, V., Andoga, R., Fozo, L., \& Judicak, J. (2012). Digital start-up control of the small turbojet engine MPM-20. Applied Machine Intelligence and Informatics (SAMI), 2012 IEEE $10^{\text {th }}$ International Symposium on IEEE / Herl'any, 277-281. https://doi.org/10.1109/SAMI.2012.6208973

[12] Baoan, L. \& Fan, Z. (2012). Modeling and Simulation of Small Turbojet Engine Ground Starting Process. Proceedings of the 2012 Second International Conference on Instrumentation, Measurement, Computer, Communication and Control. IEEE Computer Society Harbin. https://doi.org/10.1109//MCCC.2012.14

[13] Xia, C., Fu, X., Wan, Z., Huang, G., \& Chen, J. (2013). Research on windmill starting characteristics of MTE-D micro turbine engine. Chinese Journal of Aeronautics, 26(4), 858-867. https://doi.org/10.1016/j.cja.2013.06.003

[14] Montazeri-Gh, M. \& Seyed Alireza M. F. (2015). Application of Bond-Graph Method in Microjet Engine Cold Start Modeling to Investigate the Idea of Injecting Compressed Air. Trans Tech Publications - Applied Mechanics and Materials, 799. https://doi.org/10.4028/www.scientific.net/AMM.799-800.890

[15] Dub, M., Bajer, J., \& Stepanek, M. (2015). Electronic starting control unit for small jet engine. ICMT2015 International Conference IEEE, 1-4. https://doi.org/10.1109/MILTECHS.2015.7153748

[16] National Instruments. http://www.ni.com/labview/ (Accessed: 2017/3/14).

\section{Contact information}

Morteza MONTAZERI-GH, Dr. Prof.

Systems Simulation and Control Laboratory,

School of Mechanical Engineering,

Iran University of Science and Technology,

Tehran, Iran

E-mail: montazeri@iust.ac.ir

\section{Seyed Alireza Miran FASHANDI,}

Corresponding author

Systems Simulation and Control Laboratory,

School of Mechanical Engineering,

Iran University of Science and Technology,

Tehran, Iran

E-mail: alirezamiran@mecheng.iust.ac.ir

E-mail: s.alireza.miran@gmail.com

\section{Dr. Soheil JAFAR}

University Cranfield

Centre for Propulsion Engineering,

School of Aerospace, Transport and Manufacturing (SATM)

Room 505A, Whittle Building (52),

Cranfield, Bedfordshire, MK43 OAL, UK

E-mail: S.Jafari@Cranfield.ac.uk 